\title{
Video Article \\ Confocal Time Lapse Imaging as an Efficient Method for the Cytocompatibility Evaluation of Dental Composites
}

\author{
Ghania Nina Attik ${ }^{1}$, Kerstin Gritsch ${ }^{1,2}$, Pierre Colon ${ }^{1,3}$, Brigitte Grosgogeat ${ }^{1,2}$ \\ ${ }^{1}$ Laboratoire des Multimatériaux et Interfaces, UMR CNRS 5615, Université Lyon1 \\ ${ }^{2}$ UFR d'Odontologie, Université Lyon1; Service de Consultations et de Traitements Dentaires, Hospices Civils de Lyon \\ ${ }^{3}$ UFR d'Odontologie, Université Paris Diderot; Service d'Odontologie, APHP, Hôpital Rothschild
}

Correspondence to: Ghania Nina Attik at nina.attik@univ-lyon1.fr

URL: https://www.jove.com/video/51949

DOI: doi:10.3791/51949

Keywords: Medicine, Issue 93, In vitro biocompatibility, dental composites, Live/Deadstaining, 3D imaging, Confocal Microscopy, Time lapse imaging

Date Published: 11/9/2014

Citation: Attik, G.N., Gritsch, K., Colon, P., Grosgogeat, B. Confocal Time Lapse Imaging as an Efficient Method for the Cytocompatibility Evaluation of Dental Composites. J. Vis. Exp. (93), e51949, doi:10.3791/51949 (2014).

\section{Abstract}

It is generally accepted that in vitro cell material interaction is a useful criterion in the evaluation of dental material biocompatibility. The objective of this study was to use 3D CLSM time lapse confocal imaging to assess the in vitro biocompatibility of dental composites. This method provides an accurate and sensitive indication of viable cell rate in contact with dental composite extracts. The ELS extra low shrinkage, a dental composite used for direct restoration, has been taken as example. In vitro assessment was performed on cultured primary human gingival fibroblast cells using Live/Dead staining. Images were obtained with the FV10i confocal biological inverted system and analyzed with the FV10ASW 3.1 Software. Image analysis showed a very slight cytotoxicity in the presence of the tested composite after 5 hours of time lapse. A slight decrease of cell viability was shown in contact with the tested composite extracts compared to control cells. The findings highlighted the use of 3D CLSM time lapse imaging as a sensitive method to qualitatively and quantitatively evaluate the biocompatibility behavior of dental composites.

\section{Video Link}

The video component of this article can be found at https://www.jove.com/video/51949/

\section{Introduction}

One of the main standards quoted in the ISO recommendations to define biocompatibility is the absence of material toxicity to cells. Resinbased dental composites may release components from the resinous matrix, which could be initially due to partial polymerization, and/or later due to degradation processes over time ${ }^{1-4}$. These released components come into contact with oral tissues and may have various drawbacks like urticarial and mucosal reactions ${ }^{5}$, development of allergy and hypersensitivity reactions in patients ${ }^{6}$, modifications of gingival fibroblasts morphology and reduction on type I collagen protein ${ }^{7}$, immunosuppression or immunostimulation on mitogen-driven proliferation of purified T-lymphocytes and spleen cells ${ }^{8}$ and DNA damage in primary human gingival fibroblasts, which underlines their genotoxic potential ${ }^{9}$. Many parameters can affect dental composite toxicity such as the shade of the composite, the light curing, the chemical composition of the resin monomer, the filler and the degree of conversion ${ }^{10-13}$. Since in vitro toxic potential of materials may predict in vivo situations and could be compared to clinical situations by the study of some relevant endpoints. The cytotoxicity of dental composites and their components have been widely evaluated using cell culture systems ${ }^{14-16}$.

These in vitro systems have been developed to assess dental composites biocompatibility in term of: cell growth, and cell apoptosis using THP-1monocytes like cells ${ }^{17}$, cytotoxicity in human gingival fibroblasts ${ }^{18}$, inflammatory potential in HaCaT keratinocytes like cells ${ }^{2}$, cell functionality odontoblast-like MDPC-23 cells ${ }^{19}$, reduction of total RNA levels, and significant increase in induction of apoptosis on human gingival keratinocytes ${ }^{20}$ and DNA damage on gingival and pulp fibroblast cells ${ }^{21}$.

Different methodologies are suggested to investigate the biocompatibility of dental composites. Colorimetric assays, which involve specific colorants and light adsorption measurements, remain the most commonly used, due to their relative simplicity and low cost ${ }^{22-26}$. Microscopy analysis by light contrast frequently consumes more time and incurs higher costs. However, these microscopy techniques have some important advantages. The observation of cell structure gives extended information about experienced toxic effects, thus providing more relevant and sensitive data. In particular, the introduction of confocal microscopy ${ }^{27}$ has allowed for the observation of biological structures with improving axial resolution compared to traditional wide-field imaging fluorescence microscopes. Hence, confocal imaging has become a powerful investigative tool in different fields of medical and science researches. In contrast to electronic microscopy techniques, scanning confocal microscopy offers the ability to visualize distinct components of cells by incorporation of specific fluorescent markers. Most of these specific tracers are stable in an aqueous environment, sensibly measurable, inexpensive and non-toxic ${ }^{28}$, allowing their use in clinical as well as laboratory research studies. Moreover, the specimen drying and fixation required for conventional electronic microscopy analysis is not necessary for time lapse confocal imaging, thus time-dependent acquisition is also possible on samples. Compared to the two-dimensional imaging, the confocal imaging 
principle enables a specimen subsurface visualization and the three-dimensional structure reconstruction from the different obtained depth images; which result in, more precise and more structural details ${ }^{29,30}$. The present video study is an example of the use of three-dimensional Time-Lapse Confocal Laser Scanning Microscopy (3D-CLSM) combined with Live/Dead fluorescent labeling and signal quantification as an innovative method. The technique presented in this paper has the advantage of enabling sensitive evaluation and time-lapse imaging of live cells without changing the assessed cell structure. No preparation steps are required before confocal analysis. Previously, the same staining was used for assessing the viability of cultured cancellous bone cores ${ }^{31}$ but without confocal time-lapse following. Similarly the same time-lapse confocal procedure was used to assess erythromycin time-kill activity in bacteria of activated sludge according to their Gram type ${ }^{32}$ using a specific bacteria Live/dead staining. These methods have been recently adapted and used to compare the toxicity of dental composites based on methacrylate monomers ${ }^{11}$.

\section{Protocol}

The protocol consists of three major steps: the first step comprises the preparation of composite extract in culture media; the second concerns the Primary Human Gingival Fibroblasts (HGF) cell culture, the contact of cells with the composite extracts and cell staining; the third step consists of confocal imaging and the fluorescent signal analysis. For gingival tissues taking, the protocol was approved in compliance with French legislation, informed consent and local ethical committee.

\section{Composite Extracts Preparation}

Use Dulbecco's modified Eagle medium (DMEM) as the elution medium. Ensure that the ratio between the surface area of the specimens and the volume of extraction medium is at the lowest level of the ISO $10993 / 12$ requirements. The procedure is recently described ${ }^{11}$ and outlined briefly below:

1. Form spherical samples of the uncured dental composite using a bespoke holder. The holder size is $2 \mathrm{~mm}$ in radius, which is in accordance with generally advised curing depth in the oral clinical treatment.

2. Prepare plate wells, each containing $1 \mathrm{ml}$ of culture medium (DMEM), with a $5 \%$ mix of penicillin/streptomycin and $1 \%$ of amphotericin but without fetal bovine serum (FBS).

3. Cure samples within the well containing DMEM medium using a LED light lamp with a $1,070 \mathrm{~mW} \mathrm{~cm}^{-2}$ intensity $(\lambda=465-475 \mathrm{~nm})$ for $40 \mathrm{sec}$. Ensure that the distance between the curing tip and the samples is in the range of $0.5 \mathrm{~mm}$. Use this curing mode to simulate the temporary contact between tooth and the uncured dental composite. In clinical situation, the contact occurs when the restorative composite is placed in the oral cavity.

4. Incubate samples (composites specimens in DMEM medium) at $37^{\circ} \mathrm{C}$ under humidified atmosphere of $5 \% \mathrm{CO}_{2}$ in air. Incubate DMEM medium (without composite samples) for control cells in the same conditions.

\section{HGF Cell Culture, Composite Extracts Testing and Cells Staining}

1. Growth and maintenance of cell cultures

Isolate human gingival fibroblasts from healthy gingival tissue biopsies of patients taken during routine orthodontic extractions.

1. Cultivate human gingival fibroblasts in DMEM in the presence of $10 \% \mathrm{FBS}, 5 \%$ Penicillin/Streptomycin and $1 \%$ Amphotericin $\mathrm{B}$. Maintain cells at $37^{\circ} \mathrm{C}$ in incubator under a humidified atmosphere of $5 \% \mathrm{CO}_{2}$ in air.

2. Changed medium every 3 days, and passage cells every 5 days. After reaching confluency, harvest cells by trypsinization.

3. Centrifuge cells at $90 \times \mathrm{g}$ for $5 \mathrm{~min}$ and re-suspend them in the culture medium. Count cell with a scepter handheld automated cell counter.

4. Seed cell suspension at a cell density of $2.5 \times 10^{4}$ cells $/ \mathrm{ml}$ in a chamber slide system. Allow the incubation of cells overnight at $37^{\circ} \mathrm{C}$ in a $5 \%$ atmosphere.

2. Addition of composite extracts to the cells in culture

1. Replace the media of two wells of the chamber slide by $1 \mathrm{ml}$ of the tested composite extracts (after $24 \mathrm{hr}$ of incubation).

2. Maintain the two remaining wells (control cells) in the same conditions.

3. Incubate the chamber slide containing the four wells at $37^{\circ} \mathrm{C}$ in incubator, under a humidified atmosphere of $5 \% \mathrm{CO}_{2}$ in air.

3. Fluorescent staining

Use the Live/Dead cytotoxicity stain for eukaryotic cells according to the manufacturer's instructions.

NOTE: the kit provides a quick two-color fluorescent assay to determine viability of cells in a population based on plasma membrane integrity and esterase activity. The stain distinguish live from damaged cells by simultaneously labelling with green-fluorescent Calcein-AM to indicate intracellular esterase activity and red-fluorescent Ethidium homodimer-1 (EthD-1) to indicate loss of membrane integrity.

1. Prepare a working solution of the two stain reagents containing $2 \mu \mathrm{M}$ of Calcein AM and $4 \mu \mathrm{M}$ EthD-1 (final concentration reported to be suitable for fibroblast staining). Add the stain to the cultured adherent cells in the presence or absence of the selected composite extracts.

2. Observe directly and rapidly the stained cell populations at the least $15 \mathrm{~min}$ after staining and through the time-lapse imaging. Do not centrifuge and do not fixe the stained cells. 


\section{Confocal Time Lapse Imaging and Signal Analysis}

The system used is equipped with a four diode laser units and a multi-stained image for up to four fluorescent dyes for each specimen. The system can perform a mapping image (10X magnification) that gives an overview of the test sample on which one can move to observe a region of interest (600X magnification).

1. Time lapse imaging

1. Place the specimens (the chamber slide containing the stained samples) on the dark room of the confocal integrated incubator $\left(37^{\circ} \mathrm{C}\right.$, $5 \%$ of $\mathrm{CO}_{2}$ and humid atmosphere).

2. Select the corresponding lasers. Use the two laser sources $473 \mathrm{~nm}(15 \mathrm{~mW})$ and $559 \mathrm{~nm}(18 \mathrm{~mW})$ to excite Calcein and EthD-1.

3. Use a two sequential mode to acquire images through line sequences without crosstalk in imaging with the two used fluorescence dyes.

4. Use a detector with a newly developed spectrum to automatically set conditions in accordance with the fluorescence dye in scanning unit.

5. Optimize the bandwidths of the detected fluorescence for each channel to the maximum. Record all acquisitions sequentially to avoid potential cross-talking.

6. Select the most suitable imaging conditions based on the fluorescent dye selection using the acquisition software.

7. Acquire a Map image that is automatically created from the center in a spiral pattern, with the area of interest being easily selected for closer examination.

8. Select observation mode. Select up to five types of observation modes including time-lapse, Z-stack, and multi-area as needed. Use a combination of Z-stack and time-lapse modes in the present study and complete swiftly the image capturing,

9. Change and switch the fluorescent dye. Alternatively, overlay the fluorescent and the light contrast images with each other. Observe live image using the selected point on the left lower map screen.

10. Determine the imaging area by using the framing and zooming functions. Optionally, switch between the displays for each type of fluorescence dye.

NOTE: The microscope used in this protocol has the same functionality as a high conventional confocal in a compact design. The microscope is equipped with inverted water-immersion objectives which are optimally suited for stable time-lapse imaging of live cells with a simplified built-in incubator.

2. Signal analysis and quantification

1. Use the imaging software to quantify the fluorescence signal. Obtain five map images with the 10X objective for both tested sample and cell control.

2. Obtained $1,024 \times 1,024$ pixel regular images, with a $0.231 \mu \mathrm{m} \times 0.231 \mu \mathrm{m}$ pixel size. Store images as Olympus Image Format (OIF) for signal analysis. This format enables storing various parameter settings and images together. Use different analysis tools (measurement of intensity profile, intensity ratio between the two used channels).

3. Store the maximal projection images as 12 bits/pixel TIFF files.

4. Preform statistical analyses using the R commander software. Analyze differences using one-way analysis of variance (ANOVA) with a repetition test. Report results as mean standard deviation $( \pm S D)$ and statistical significance at $p<0.05$.

\section{Representative Results}

Figure 1 showed an overview of the Live/Dead stained cells in obtained mapping images (10X objective) for both control and cells exposed to the tested composite extracts (ELS extra low shrinkage). The three dimensional structure of the cells could be visualized at the magnification $600 X$. Visualization of cells collected in the control chamber and of cells collected in the chamber in the presence of the tested composite extracts is presented in Figure 2. The maximal projection (objective 60X) shows the fate of selected cell populations at the start of the time lapse (at $15 \mathrm{~min}$ ) and at the end of the time lapse period (at $5 \mathrm{hr}$ ). Fifty seven stacks of images (xyzt mod scan, 39 images per stacks, voxeldepth $1.00 \mu \mathrm{m}$ ) were obtained during this period. A slight decrease in the green fluorescent signal and very slight variation in the red fluorescent were obtained in exposed cells. No significant variation was observed for control cells. Composite extracts exposed cells assumed similar spindle morphology to control cells; morphology was not altered in these experimental conditions (despite the green signal decrease and the red signal increase in the presence of the tested composite). Image analysis was performed on five selected different image stacks corresponding to different cell populations from the obtained images for the tested composite as compared to negative control cells for both green and red signal. The intensity profile of stained cells is illustrated in Figure 3; the green and red signal evolution of the cells in contact with the tested composite was comparable to those of control cells. Calcein and EthD-1 fluorescence emission intensities were measured on control cells and on composite exposed cells. The measurement was done at one hour intervals for up to five hr. The green/red fluorescence ratio (based on integrated intensities of the green $495-515 \mathrm{~nm}$ and red $620-650 \mathrm{~nm}$ signals) was calculated during the time-lapse period. The viability ratios for control and exposed cells to ELS extra low shrinkage extracts are shown in the Table 1. In the presence of the tested composite, the percentage of live cells was found to decrease slightly from $100 \%$ to $93.9 \%$ after $1 \mathrm{hr}$ of contact. Significant difference was observed between the tested composite and the negative control (cells without any composite extracts) after $5 \mathrm{hr}$ of the indicated time-lapse period. 

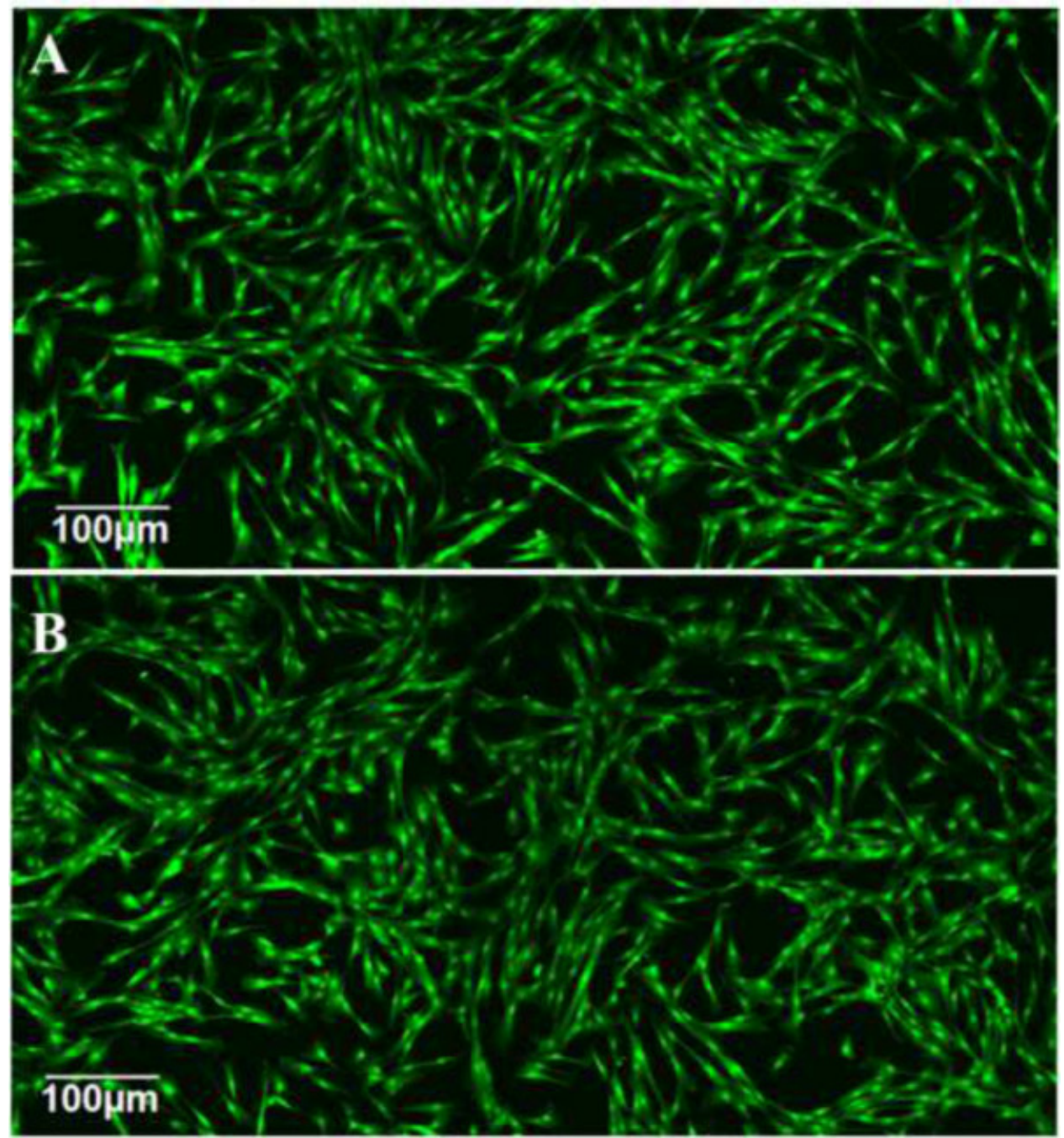

Figure 1: Overview of mapping image showed stained cells at objective 10X, (A) control cells and (B) cells in presence of composite extracts (ELS extra low shrinkage) in the beginning of the time lapse period $(t=15 \mathrm{~min})$. Green areas are live cells and red areas are damaged cells. In this experiment conditions, no variation (for both green and red fluorescence) was observed for composites exposed cells compared to negative control cells. 

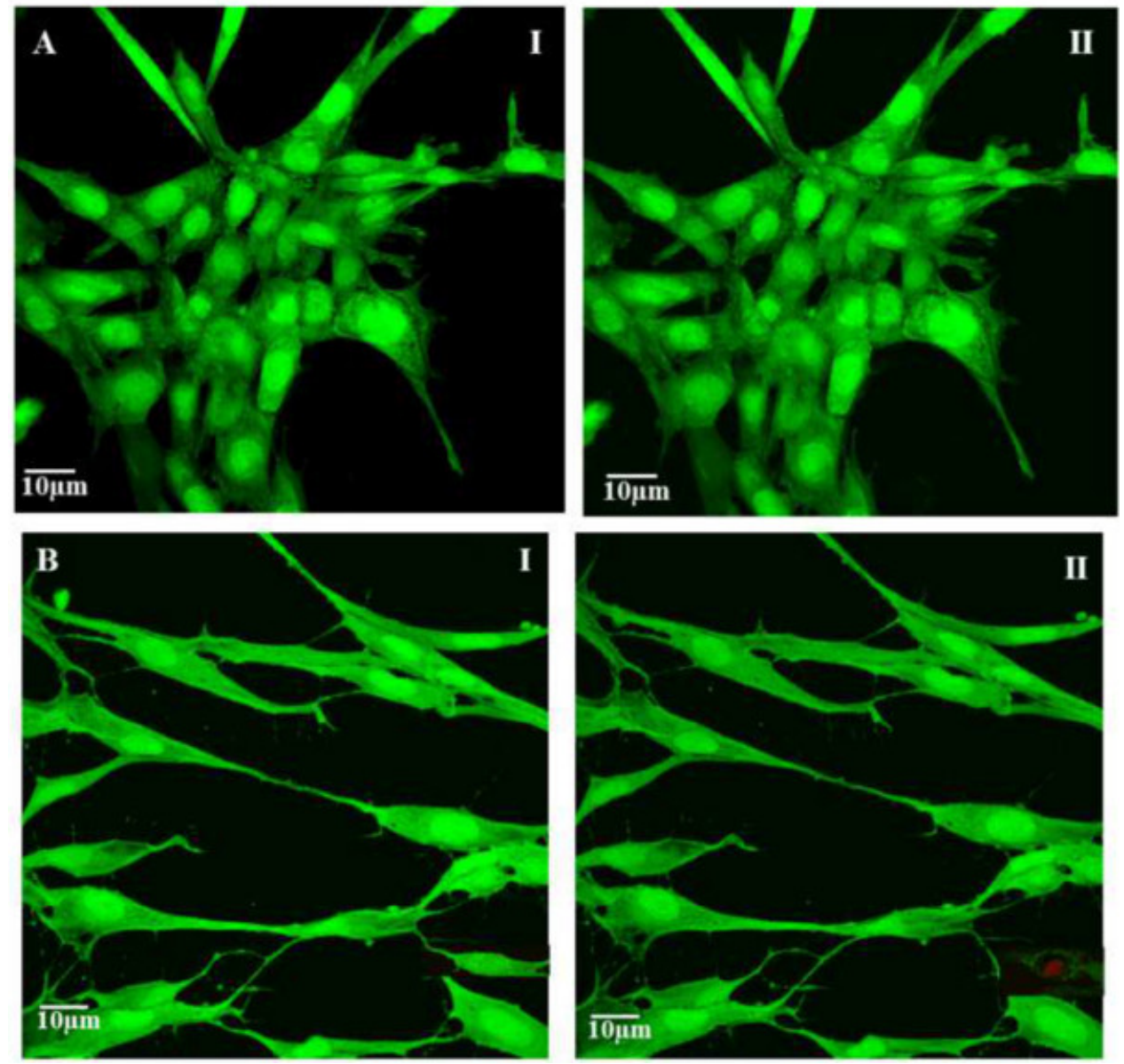

Figure 2: CLSM images at objective 60X of a cell population from (A) control chamber and (B) composite extracts chamber in the beginning and the end of the exposure time-lapse period (I: $15 \mathrm{~min}$ and II: $5 \mathrm{hr}$, respectively). Green areas are live cells and red areas are damaged cells. The panel of the images demonstrated slight change in the intensity signal (slight decrease in the green signal and very slight increase in the red one). No cell morphology alterations were observed in the presence of composite extracts; expose cells maintained their spindle-shaped and fibroblastic morphology as control cells.

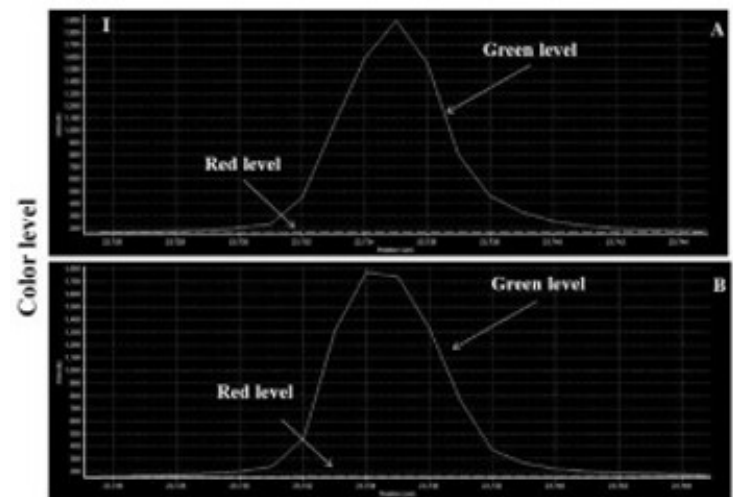

$\mathrm{X}$ position ( $\mu \mathrm{m})$

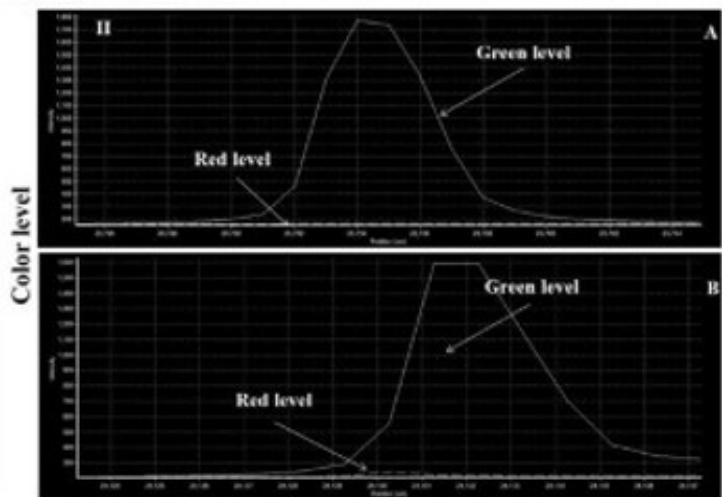

X position $(\mu \mathrm{m})$

Figure 3: Line profile of cells observed in time-lapse microscopy. (A) Control cells (B) Composite extracts exposed cells, (I) at 15 min and (II) at $5 \mathrm{hr}$. No visible variation in the green signal evolution in the presence of tested composite regardless the time contact. However, slight increase of the red signal was observed in the presence of composite after $5 \mathrm{hr}$ of contact.

\begin{tabular}{|l|l|l|l|l|l|}
\hline \multirow{2}{*}{ Contact time (hour) } & \multicolumn{5}{|l|}{ Cell Viability (\%) } \\
\cline { 2 - 7 } & 1 & 2 & 3 & 4 & 5 \\
\hline Control cells & 100 & 100 & 100 & 100 & 100 \\
\hline
\end{tabular}




\begin{tabular}{|l|l|l|l|l|l|}
\hline $\begin{array}{l}\text { ELS extra low } \\
\text { shrinkage }\end{array}$ & $93.9 \pm 7$ & $91.3 \pm 5^{\star}$ & $89.5 \pm 3^{*}$ & $87.6 \pm 2^{*}$ & $87.7 \pm 3^{*}$ \\
\hline
\end{tabular}

Table 1: Rate of live HGF cells evolution after 1, 2, 3, 4 and $5 \mathrm{hr}$ of contact with composite extracts. Cell viability was assayed by staining using the Live/Dead cytotoxicity kit. Data show mean values \pm SD of five images stacks analysis. Values are significantly different from control cells at $p<0.05$.

\section{Discussion}

Biocompatibility material behavior is the most prerequisite parameter to be evaluated before medical use. International standards cover medical devices ISO $10993^{33}$ and specifically dental materials ISO $7405^{34}$. The absence of the toxic effects to the surrounding cells is the key norm in the biocompatibility evaluation of such materials. That is why cytotoxicity testing has such importance in the assessment of dental material biocompatibility ${ }^{35-37}$. The ISO suggested testing methods could be based on metabolic activity or membrane integrity. Selected endpoints should follow specific conditions for ranking adverse effects induced by a test material in order to minimize the time and the cost of the assessment assays. The current method of investigation (3D confocal time lapse imaging) is membrane integrity based. The cytotoxicity evaluation via this endpoint seems to be a valuable marker of cell biocompatibility with tested materials and it is also ISO approved endpoint. In vitro tests are designed to determine how a material sample affects a particular cell type. The colorimetric MTT assay was originally described by Mossman (1983) as a useful method for the measurement of in vitro cytotoxicity and cell proliferation. The MTT test is based on the conversion of the tetrazolium salt into formazan crystals by active cells, which determines mitochondrial activity. This can be translated by viability rate ${ }^{38}$ Gupta and collaborators reported that the MTT test is the most widely used method for measuring cytotoxicity of composite resins. Succinic dehydrogenase and alkaline phosphatase responses have also been used for the same purpose ${ }^{39}$. However, the fate cells cannot be followed up, since the MTT assay requires killing the cells at each measurement time point. In order to monitor more closely the behavior of the stained cells in the current study, direct observation of live cells was performed, thanks to time lapse CLSM imaging combined with a short protocol staining, automated image analysis and fluorescent signal quantification.

Dental composites come in close contact with oral tissues, especially gingival and pulpal cells. Fibroblasts would be the target of components released from these restorative composites ${ }^{40-41}$. Furthermore, several studies have reported that immortalized cells and primary cells may have different cellular responses in contact with biomaterials. Primary cells were found to be more appropriate to assess biomaterials effects ${ }^{42}$. This explains the use of primary human gingival fibroblast cells as cell model for cytotoxicity assessment of the tested dental composite in the current study. The toxicity potential of the released substances from dental composite has been widely studied ${ }^{43-44}$. In order to assess the cytotoxic potential of materials, two contact model cells could be performed. In the direct contact model system the material is directly placed with target cells while in the indirect contact system, target cells are in contact with elutes from biological media. In clinical applications and for restorative procedures, dental composite are placed in indirect contact with gingival tissues. For this reason, the current experimental protocol was focused on the indirect contact system with human gingival fibroblasts (cells in presence of the tested composite extracts). As previously reported by Dahl and collaborators, cytotoxicity responses were ranked as severe $(<30 \%)$, moderate $(30-60 \%)$, slight $(60-90 \%)$ or non-cytotoxic $(>90 \%)$ based on the activity relative to values obtained for the controls ${ }^{45}$. Therefore, according to this ranking and in the light of the obtained results (Table 1 ), composite ELS extra low shrinkage could be ranked as very slightly cytotoxic and showed comparable behavior to control cells during the entire time lapse period. Using the precisely same investigation method, the results of this study could be compared to those of a recently published study. The ELS extra low shrinkage composite demonstrated superior biocompatibility compared to the two previously tested composites used for the same clinical application that is the direct restoration ${ }^{11}$. Further studies are still necessary to establish more complete comparison.

When deciding which cytotoxicity assay to approve for a specific endpoint assessment, it is important to understand the advantages and the limitations of each assay. The main purpose of confocal imaging is to achieve a 3-D architecture of cells and organs. The technique is able to reveal not only a specimen's surface, but also its subsurface. The protocol described herein underlines the use of 3D CLSM time lapse confocal imaging, as a sensitive method to assess the in vitro biocompatibility behavior of a dental composite. However, in order to avoid the limitations encountered in this work, Anti-vibration workstations could be used in order to allow more stable and longer time lapse imaging; the tabletop could isolate the used confocal system from the detrimental effects that vibrations in the lab may cause. Furthermore, materials to be used in the oral cavity should ideally be harmless to the gingival tissues and should contain no substances that could cause systemic toxicity. In accordance with the methodology used and the results obtained from the current study it can be concluded that the tested composite (ELS extra low shrinkage) is not cytotoxic in the present experimental conditions. As the CLSM method can sensitively give the initial rate of viable cells, other possibilities could be foreseen to assess more endpoints. In particular, as it has been recently reported that composite monomers affect cells through reactive oxygen species (ROS) ${ }^{46-48}$, further investigation is needed to assess correlations if any between cytotoxicity signaling networks and ROS production. The future protocol could be designed to simultaneously evaluate ROS production $\left(\mathrm{H}_{2} \mathrm{O}_{2}\right.$ and/or $\mathrm{O}_{2}^{-}$staining) and cytotoxicity ratio (Live/dead staining) using time lapse CLSM imaging.

\section{Disclosures}

The authors declare that they have no competing financial interests, they have nothing to disclose.

\section{Acknowledgements}

Saremco Dental Switzerland and Olympus Microsystems France Companies are gratefully acknowledged for their financial support. Saremco Dental is also acknowledged for the generous donation of the dental composites ELS extra low shrinkage. The authors also wish to express their appreciation to Dr Simon Banks from the department of Chemistry (University College London) for his assistance with English revision. 


\section{References}

1. Van Landuyt, K.L. et al. How much do resin-based dental materials release? A meta-analytical approach. Dent. Mater. 27 (8), 723-747, 10.1016/j.dental.2011.05.001, (2011).

2. Moharamzadeh, K., Van Noort, R., Brook, I.M., \& Scutt, A.M. Cytotoxicity of resin monomers on human gingival fibroblasts and HaCaT keratinocytes. Dent. Mater. 23 (1), 40-44, (2007).

3. Santerre, J.P., Shajii, L., \& Leung, B.W. Relation of dental composite formulations to their degradation and the release of hydrolyzed polymeric-resin-derived products. Crit. Rev. Oral Biol. Med. 1 2(2), 136-51, (2001).

4. Geurtsen, W. Biocompatibility of resin-modified filling materials. Crit. Rev. Oral Biol. Med. 11 (3), 333-355, (2000).

5. Hensten-Pettersen, A. Skin and mucosal reactions associated with dental materials. Eur. J. Oral Sci. 106 (2Pt2), 707-712, (1998).

6. Paranjpe, A., Sung, E.C., Cacalano, N.A., Hume, W.R., \& Jewett, A. N-acetyl cysteine protects pulp cells from resin toxins in vivo. J. Dent. Res. 87 (6), 537-541, (2008).

7. Falconi, M., Teti, G., Zago, M., Pelotti, S., Breschi, L., \& Mazzotti, G. Effects of HEMA on type I collagen protein in human gingival fibroblasts Cell. Biol. Toxicol. 23 (5), 313-322, (2007).

8. Jontell, M., Hanks, C.T., Bratel, J., \& Bergenholtz, G. Effects of unpolymerized resin components on the function of accessory cells derived from the rat incisor pulp. J. Dent. Res. 74 (5), 1162-1167, (1995).

9. Urcan, E., Scherthan, H., Styllou, M., Haertel, U., Hickel, R., \& Reichl, F.-X. Induction of DNA double-strand breaks in primary gingival fibroblasts by exposure to dental resin composites. Biomaterials. 31 (8), 2010-2014,doi: 10.1016/j.biomaterials, (2010).

10. Sigusch, B.W et al.Resin-composite cytotoxicity varies with shade and irradiance. Dent. Mater. 28 (3), 312-319,doi: 10.1016/ j.dental.2011.12.007, (2012).

11. Attik, G.N., Pradelle-Plasse, N., Campos, D., Colon, P., \& Grosgogeat, B., Toxicity Evaluation of Two Dental Composites: ThreeDimensional Confocal Laser Scanning Microscopy Time-Lapse Imaging of Cell Behavior. Microsc. Microanal. 19, 596-607, doi:10.1017/ S1431927613000433, (2013).

12. Ausiello, P. et al. Cytotoxicity of dental resin composites: an in vitro evaluation. J. Appl. Toxicol. 33(6), 451-7, doi:10.1002/jat.1765, (2011).

13. Durner, D., Obermaier, J., Draenert, M., \& llie, N. Correlation of the degree of conversion with the amount of elutable substances in nanohybrid dental composites. Dent. Mat. 28 (11), 1146-1153,doi: 10.1016/j.dental.2012.08.006, (2013).

14. Sigusch, B.W., Völpel, A., Braun, I., Uhl, A., \& Jandt, K.D. Influence of different light curing units on the cytotoxicity of various dental composites. Dent. Mater. 23 (11), 1342-1348, (2007).

15. Knezevic, A., Zeljezic, D., Kopjar, N., \& Tarle, Z. Influence of curing mode intensities on cell culture cytotoxicity/genotoxicity. Am. J. Dent. 22 (1), 43-48, (2009)

16. Krifka, S., Seidenader, C., Hiller, K.-A., Schmalz, G., \& Schweikl, H. Oxidative stress and cytotoxicity generated by dental composites in human pulp cells. Clin. Oral Investig. 16 (1), 215-224, doi: 10.1007/s00784-010-0508-5, (2012).

17. Harorli, O.-T., Bayindir, Y.-Z., Altunkaynak, Z., \& Tatar, A. Cytotoxic effects of TEGDMA on THP-1 cells in vitro. Med. Oral Patol. Oral Cir. Bucal. 14 (9), e489-493, (2009).

18. Reichl, F.X et al. Cytotoxicity of dental composite (co)monomers and the amalgam component $\mathrm{Hg}(2+)$ in human gingival fibroblasts. Arch. Toxicol. 80 (8), 465-472, (2006).

19. Aranha, A.M.F., Giro, E.M.A., Hebling, J., Lessa, F.C.R., \& Costa, C.A. de S. Effects of light-curing time on the cytotoxicity of a restorative composite resin on odontoblast-like cells. J. Appl. Oral Sci. 18 (5), 461-466, (2010).

20. Schulz, S.D., König, A., Steinberg, T., Tomakidi, P., Hellwig, E., \& Polydorou, O. Human gingival keratinocyte response to substances eluted from Silorane composite material reveal impact on cell behavior reflected by RNA levels and induction of apoptosis. Dent. Mater. $\mathbf{2 8}(\mathbf{8})$, e135-42, doi: 10.1016/j.dental.2012.04.018, (2012).

21. Tadin, A., Marovic, D., Galic, N., Kovacic, I., \& Zeljezic, D. Composite-induced toxicity in human gingival and pulp fibroblast cells. Acta Odontol. Scand. 72 (4),304-11, doi:10.3109/00016357.2013.824607, (2014).

22. Schweikl, H., \& Schmalz, G. Toxicity parameters for cytotoxicity testing of dental materials in two different mammalian cell lines. Eur. J. Oral Sci. 104 (3), 292-299, (1996).

23. Issa, Y., Watts, D.C., Brunton, P.A., Waters, C.M., \& Duxbury, A.J. Resin composite monomers alter MTT and LDH activity of human gingival fibroblasts in vitro. Dent. Mater. 20 (1), 12-20, (2004).

24. Brambilla, E., Gagliani, M., Ionescu, A., Fadini, L., \& García-Godoy, F. The influence of light-curing time on the bacterial colonization of resin composite surfaces. Dent. Mater. 25, 1067-1072, doi: 10.1016/j.dental.2009.02.012, (2009).

25. Modareszadeh, M.R., et al. Cytotoxicity of set polymer nanocomposite resin root-end filling materials. Int. Endod. J. 44, 154-161, doi: 10.1111/j.1365-2591.2010.01825.x, (2011).

26. Tamilselvam, S., Divyanand, M.J., \& Neelakantan, P. Biocompatibility of a conventional glass ionomer, ceramic reinforced glass ionomer, giomer and resin composite to fibroblasts: in vitro study. J. Clin Pediatr. Dent. 37(4), 403-6, (2013).

27. White, J.G., Amos, W.B., \& Fordham, M. An evaluation of confocal versus conventional imaging of biological structures by fluorescence light microscopy. J. Cell Biol. 105 (1), 41-48, (1987).

28. Alpino, P.H.P., Pereira, J.C., Svizero, N.R., Rueggeberg, F.A., \& Pashley, D.H. Use of fluorescent compounds in assessing bonded resinbased restorations: a literature review. J. Dent. 34 (9), 623-634, (2006).

29. Chen, Y., Liang, C-P., Liu, Y., Fischer, A.H., Parwani, A.V., \& Pantanowitz, L. Review of advanced imaging techniques. J. Pathol. Inform. 3 , 22, doi: 10.4103/2153-3539.96751, (2012).

30. Ishikawa-Ankerhold, H.C., Ankerhold, R., \& Drummen, G.P.C. Advanced Fluorescence Microscopy Techniques-FRAP, FLIP, FLAP, FRET and FLIM. Molecules. 17 (4), 4047-4132, doi:10.3390/molecules17044047, (2012).

31. Stoddart, M.J., Furlong, P.I., Simpson, A., Davies, C.M., \& Richards, R.G. A comparison of non-radioactive methods for assessing viability in ex vivo cultured cancellous bone: technical note. Eur. Cell Mater. 12, 16-25, (2006).

32. Louvet, J.N., Attik, G., Dumas, D., Potier, O., \& Pons, M.N. Simultaneous Gram and viability staining on activated sludge exposed to erythromycin: 3D CLSM time-lapse imaging of bacterial disintegration. Int. J. Hyg. Environ. Health. 214 (6), 470-477, doi: 10.1016/ j.ijheh.2011.02.001, (2011). 
33. Dentistry - Preclinical evaluation of biocompatibility of medical devices used in dentistry - Test methods for dental materials. International Standards Organization. (2009).

34. Biological evaluation of dental devices. International Standards Organization. (2009).

35. Elshahawy, W.M., Watanabe, I., \& Kramer, P. In vitro cytotoxicity evaluation of elemental ions released from different prosthodontic material. Dent. Mater. 25 (12), 1551-1556, doi: 10.1016/j.dental.2009.07.008, (2009).

36. Williams, D.F. On the mechanisms of biocompatibility. Biomaterials. 29(20), 2941-2953, doi: 10.1016/j.biomaterials.2008.04.023, (2008).

37. Illeperuma, R.P et al. Immortalized gingival fibroblasts as a cytotoxicity test model for dental materials. J. Mater. Sci. Mater. Med. 23(3), 753762, doi: 10.1007/s10856-011-4473-6, (2012).

38. Wataha, J.C., Lockwood, P.E., Bouillaguet, S., \& Noda, M. In vitro biological response to core and flowable dental restorative materials. Dent. Mater. 19 (1), 25-31, (2003).

39. Ergun, G., Egilmez, F., \& Yilmaz, S. Effect of reduced exposure times on the cytotoxicity of resin luting cements cured by high-power led. J. Appl. Oral Sci. 19 (3), 286-292, (2011).

40. Yap, A.U., Han, V.T., Soh, M.S., \& Siow, K.S. Elution of leachable components from composites after LED and halogen light irradiation. Operative Dentistry. 29 (4), 448-53, (2004)

41. Lee, S.Y., Greener, E.H., \& Menis, D.L. Detection of leached moieties from dental composites in fluids stimulating food and saliva. Dent. Mat. 11 (6), 348-53, (1995).

42. Anselme, K., Davidson, P., Popa, A.M., Giazzon, M., Liley, M., \& Ploux, L. The interaction of cells and bacteria with surfaces structured at the nanometre scale. Acta Biomateriala Journa. 6 (10), 3824-46, doi: 10.1016/j.actbio.2010.04.001, (2010).

43. Mosmann, T. Rapid colorimetric assay for cellular growth and survival: application to proliferation and cytotoxicity assays. J. Immunol. Methods. 65 (1-2), 55-63, (1983).

44. Gupta, S.K., Saxena, P., Pant, V.A., \& Pant, A.B. Release and toxicity of dental resin composite. Toxicol. Int. 19(3), 225-234, doi: 10.4103/0971-6580.103652, (2012).

45. Dahl, J.E., Frangou-Polyzois, M.J., \& Polyzois, G.L. In vitro biocompatibility of denture relining materials. Gerodontology. 23(1), 17-22, (2006)

46. Krifka, S., Seidenader, C., Hiller, K.A., Schmalz, G., \& Schweikl, H. Oxidative stress and cytotoxicity generated by dental composites in human pulp cells. Clin. Oral Investig. 16(1), 215-24, doi: 10.1007/s00784-010-0508-5, (2012).

47. Krifka, S., Spagnuolo, G., Schmalz, G., \& Schweikl, H. A review of adaptive mechanisms in cell responses towards oxidative stress caused by dental resin monomers. Biomaterials. 34 (19), 4555-4563, doi: 10.1016/j.biomaterials.2013.03.019, (2013).

48. Chang, M.C., et al. The role of reactive oxygen species and hemeoxygenase- 1 expression in the cytotoxicity, cell cycle alteration and apoptosis of dental pulp cells induced by BisGMA. Biomaterials. 31, 8164-8171,doi: 10.1016/j.biomaterials.2010.07.049, (2010). 